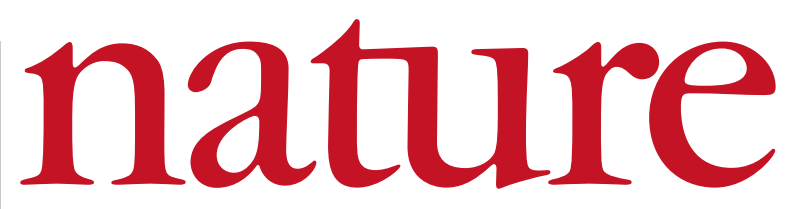

11 March 2004 Volume 428 Issue no 6979

\title{
Time for a French revolution
}

France's scientists take to the streets more readily than most, but are now rightly confronting a neglectful government. They should resist short-term concessions unless these help to secure the long-term health of research.

\section{6 \\ T} he commitment to research must be historic." That's what French president Jacques Chirac pledged in his 2002 election manifesto, calling for science spending to jump from $2.2 \%$ of gross domestic product (GDP) to $3 \%$ by 2010 . His term of office has indeed been historic: historic slashes in science budgets, historic cuts in opportunities for young scientists, and, of late, historic numbers of scientists protesting in the boulevards.

So French scientists fell off their lab stools in disbelief on 6 January when Chirac, in his new-year address, had the gall to reaffirm that research was a national priority, when it was obviously anything but. His speech galvanized a simmering revolt, the Save Research movement, whose petition, launched two days later, has been signed by 66,000 researchers - two-thirds of the entire scientific workforce.

The signatories threatened to resign this week from all management duties, bringing French science to a halt, unless the government redresses a financial crisis at the research agencies, and reinstates 550 full-time research posts that have been turned into short-term contracts (see page 108).

This is far from mere selfishness. The movement is grassroots, emerging independently of trade unions. Its rallying call is that neglect of science is turning away a generation of bright young minds, and that national science policy is adrift. It is right on both counts.

One of its key demands is a thorough overhaul of France's outdated and inefficient science system. The movement has struck a nerve, garnering unprecedented support from the youngest postgraduates to France's star scientists. The momentum for change must not belost.

Jean-Pierre Raffarin, the prime minister, at first bluntly dismissed the researchers' claims as false, and irritated researchers further by then announcing $€ 1.5$ billion (US\$1.9 billion) in tax subsidies to French restaurants. But he is now having to sit up and listen. The government's calculation that the revolt would peter out has so far proved wrong. For the first time that anyone can remember, research politics is regular headline news and public support is strong.

The administration has been dragged to the negotiating table, and is making concessions. It says it will fork out $€ 294$ million of the money it owes research agencies, create 120 full-time posts, boost the value of short-term contracts, and involve researchers in drafting a white paper on science promised by Chirac by the end of the year. Last weekend, Raffarin also pledged an extra $€ 3$ billion in research spending, but not until next year. We've heard that one before.

Many in government believe that public spending on research is already sufficient, arguing that it already meets the EU target of 1\% of GDP. But this is disingenuous: most goes on France's huge nuclear, space and aeronautics industries. The government has no long-term vision for basic research, and there is little reason to believe it has any intention of developing one. Conservative governments over the past two decades have consistently neglected science. Researchers have good reasons to suspect that the government is seeking to douse the flames of revolt, and then return to business as usual.

The Save Research movement is the best opportunity France has had in a long time to give scientists a strong voice in long-term discussions with government to develop new directions for the country's research, where increased funding is tied to reform of France's bloated and bureaucratic science system. This could culminate in a white paper laying the foundations for a rejuvenation of French science.

To do this, Save Research must remain united. The government's concessions may tempt many scientists to pocket their winnings and return to their labs. But they should hold out for substantial improvements. Better to allow French science to crash, and restart on a sounder footing, than to let it slip slowly into neglectful decay.

\section{Enhancing Nature's services}

\section{Introducing greater opportunity for feedback and improved navigation to relevant literature.}

U nsurprisingly, Nature's Letters and Articles frequently stimulate responses from the authors' peers. In particular, a reader may submit an attack on the core of a paper. It is then our duty to take it up with authors and referees. If the attack turns out to be well founded, a retraction or correction will follow.

If the criticism is significant but is contested, we publish it in our Brief Communications Arising (BCA) section with a response from the authors. Until now, space limitations have restricted our ability to publish all but the most significant of such debates. But from next week's issue we shall be increasing the number of such BCAs by publishing them online only, drawing attention to them by their titles and authors in the print edition's Brief Communications section and our table of contents. The BCAs will be citable by their Digital Object Identifiers, like all Nature content, and forward-linked from the original paper. This expansion will also allow us occasionally to publish comments that are more positively stimulating.

Such feedback needs no prompting. In contrast, in another enhancement, we wish to solicit feedback from authors of our papers in order to improve the service that they receive. Thus, from 1 January this year, all authors are being invited to complete an online feedback form about aspects of editorial services, from refereeing quality to efficiency and transparency in handling.

And there are two improvements in navigation for readers. One relates to our research papers. Many carry additional information for specialists in their online Supplementary Information, which has become more extensive in recent years. Readers will find that the presentation of this has been redesigned for quicker and easier access.

And finally (for now), we have introduced new internal search (or 'semantic matching') technology that allows us to scan the complete online content of Nature journals and automatically generate updated web links to related articles on request via a click on the left-hand margin of online Nature content.

As always, Nature welcomes readers' comments about these enhancements, and suggestions for others. 